\title{
Biomass Recalcitrance in Willow Under Two Biological Conversion Paradigms: Enzymatic Hydrolysis and Anaerobic Digestion
}

\author{
Jonas A. Ohlsson ${ }^{1}$ (D) Anne E. Harman-Ware ${ }^{2}$ (D) Mats Sandgren ${ }^{1}$ (D) $\cdot$ Anna Schnürer $^{1}$ (D)
}

Published online: 7 December 2019

(C) The Author(s) 2019

\begin{abstract}
Biomass recalcitrance, the inherent resistance of plants towards deconstruction, negatively affects the viability of biorefineries. This trait is not only dictated by the properties of the biomass but also by the conversion system used and its interactions with specific features of the biomass. Here, biomass recalcitrance to anaerobic digestion (AD) was assessed using a biomethanation potential (BMP) assay. Plant material $(n=94)$ was selected from a large population of natural Salix viminalis accessions, previously evaluated for biomass recalcitrance using hydrothermal pretreatment-enzymatic hydrolysis. Correlations between yields from the two biological conversion systems were evaluated, as well as the influence of biomass compositional features, analyzed by pyrolysis-molecular beam mass spectrometry (py-MBMS), and other biomass physical properties on conversion performance. BMP values averaged $198.0 \mathrm{Nml} \mathrm{CH}_{4} / \mathrm{g}$ biomass after 94 days, ranging from 28.6 to 245.9. S lignin and carbohydrate-derived spectral features were positively correlated with performance under both systems, whereas $\mathrm{G}$ lignin, $p$ coumaric acid, and ferulic acid-derived ions were negatively correlated with yields and rates. Most spectral features were more strongly correlated with enzymatic hydrolysis yields compared to methane production. For early-stage methane production and rate, recalcitrance factors were similar compared to enzymatic hydrolysis, with weaker correlations observed at later timepoints. The results suggest that although variation in methane potential was considerably lower than enzymatic hydrolysis yields, a reduced recalcitrance under this system will still be of importance to improve early conversion rates. Spectral features of low methane-producing samples indicate the presence of inhibitory substances, warranting further study.
\end{abstract}

Keywords Salix viminalis · Biomass recalcitrance · Anaerobic digestion - Biomethanation potential $\cdot$ Enzymatic hydrolysis · Analytical pyrolysis

\section{Introduction}

Biorefineries convert renewable biomass resources such as energy crops, plant residues, and organic wastes into several

Anna Schnürer

anna.schnurer@slu.se

Jonas A. Ohlsson

jonas.ohlsson@slu.se

Anne E. Harman-Ware

anne.ware@nrel.gov

Mats Sandgren

mats.sandgren@slu.se

1 Department of Molecular Sciences, Swedish University of Agricultural Sciences, Uppsala, Sweden

2 Center for Bioenergy Innovation, Biosciences Center, National Renewable Energy Laboratory, Golden, CO, USA value streams, including transportation fuels and high-value chemicals, and are likely to play an important role in future low-carbon energy systems [1]. The energy accumulated yearly in plant biomass on land may, according to one estimate, provide $20-30 \%$ of the world's energy demand in 2050 [2]. However, for many feedstocks, the inherent resistance to degradation, known as biomass recalcitrance, remains a key barrier to their use in the biorefinery, as more recalcitrant feedstocks require larger pretreatment energy inputs in order to render the substrate amenable to microbial conversion [3]. In lignocellulosic biomass, recalcitrance is believed to be highly multifactorial, encompassing both molecular and structural properties, with many key traits affecting this property primarily relating to cellulose accessibility and lignin composition $[4,5]$. Biomass recalcitrance has attracted large scientific interest (see, e.g., [3-5]) but is most commonly studied using fungal cellulases in concert with thermochemical pretreatment (hereafter referred to as enzymatic hydrolysis, EH). Consequently, recalcitrance as it relates specifically to other 
biological conversion systems, such as anaerobic digestion (AD) or consolidated bioprocessing (CBP), is less understood. Moreover, different biomass conversion systems may be distinguished by properties that could modulate the influence of certain recalcitrance features. Such properties may include the type and degree of pretreatment (e.g., hydrothermal pretreatment vs. only comminution) $[6,7]$, the origin of hydrolytic enzymes (fungal vs. bacterial) [8], substrate utilization (e.g., only hexose sugars or a broader spectrum of compounds), the presence of metabolically active microorganisms, and process temperature. These differences make interpolations of recalcitrance from one system to another difficult.

In $\mathrm{AD}$, substrates are deconstructed by microbial consortia into an energy-rich gas mixture consisting of methane $\left(\mathrm{CH}_{4}\right)$ and carbon dioxide $\left(\mathrm{CO}_{2}\right)$ and a nutrient-rich digestion residue, digestate, which can be used as fertilizer [9]. The metabolic processes occurring in an $\mathrm{AD}$ process can be divided into four steps: hydrolysis, wherein complex polymers are converted into their monomeric constituents; acidogenesis, metabolizing these monomers into $\mathrm{C} 2-\mathrm{C} 6$ compounds; acetogenesis, converting the products of the previous reaction into acetate, $\mathrm{CO}_{2}$, and $\mathrm{H}_{2}$; and finally methanogenesis [9]. The kinetics of this process will differ depending on the type of substrate used, but for materials such as lignocellulose, the hydrolysis step is generally considered ratelimiting [10]. AD has traditionally been utilized as a waste treatment and energy production method, which continues to be its main use case today $[11,12]$. However, recent attention has also been directed towards harnessing the thorough deconstruction of biomass that is the hallmark of the $\mathrm{AD}$ system, combined with its technological maturity and low costs, for production of highvalue chemicals such as carboxylates and polyhydroxyalkanoates (PHA) [13-16], hydrogen gas [16], and cellulosic ethanol $[6,7]$. Moreover, grid injection of biomethane for load balancing can be an important feature of low-carbon energy systems [12], as an increasing proportion of wind and solar in the energy mix introduces greater fluctuations in energy availability and price. In $\mathrm{AD}$, many recalcitrance studies concern the effect of pretreatments, while there is a dearth of studies investigating structural and chemical features of the biomass (for an AD-centric review, see [17]). However, a better understanding of how feedstock recalcitrance features specifically relate to $\mathrm{AD}$ may become more important as the technology is employed in further contexts.

Aside from the financial benefits of more complete substrate conversion, using lower-recalcitrance feedstocks for $\mathrm{AD}$ will, by definition, reduce the amount of organic matter in the digestate. Digestate can contain considerable amounts of volatile solids (reviewed in [18]), and its storage is a major contributor to unwanted methane emissions from biogas plants [19]. The use of lower-recalcitrance feedstocks may decrease the inadvertent release of this potent greenhouse gas (GHG) by allowing less carbon to pass unconverted through the digester. Thus, lowering feedstock recalcitrance for $\mathrm{AD}$ may improve the performance of this technology through the compound action of increased conversion efficiency and reduced post-digestion emissions.

Several recent studies have tried to shed light on the correlations between conversion yields under $\mathrm{EH}$ and $\mathrm{AD}$, highlighting the difficulties in translating measures of recalcitrance between the two paradigms. In one study comparing $\mathrm{AD}$ biomethanation potential (BMP) with $\mathrm{EH}$ yields from Miscanthus, using only mechanical pretreatment for the $\mathrm{AD}$ samples and hydrothermal pretreatment for $\mathrm{EH}$, essentially no correlation was found between outputs from the two systems [20]. On the other hand, Horn et al. [21] reported a nearperfect correlation between methane yields from $\mathrm{AD}$ and $\mathrm{EH}$ yields when using steam-pretreated Salix as the feedstock. A near-perfect correlation between $\mathrm{EH}$ and $\mathrm{AD}$ yields was also reported in four untreated substrates, including herbaceous biomass and yard waste [22], although in a similar study using both woody and herbaceous materials, a strong correlation was only found for the woody biomass, albeit encompassing only three samples [23]. Holwerda and co-workers compared three different conversion systems using three different switchgrass varieties genetically modified for reduced recalcitrance and found the effect of each modification to be highly dependent upon the conversion system used [24]. In another study, three hydrothermally pretreated poplar natural variants with differing recalcitrance profiles were studied [25]. It was found that whereas the two low-recalcitrance variants were deconstructed to a similar degree by both high-dose EH and Clostridium thermocellum, the latter system was better able to decompose the high-recalcitrance feedstock. In summary, the findings reported so far are inconclusive and contradictory, and multiple methodological differences make comparisons between studies difficult.

The overall aim of the present study was to characterize $\mathrm{AD}$ recalcitrance in a subset of a population of natural Salix viminalis accessions, previously characterized for $\mathrm{EH}$ recalcitrance, in order to elucidate relationships between performance under the two systems and assess whether this natural population could potentially serve as a source of genetic material for breeding towards improved AD performance of Salix. Moreover, this study sought to investigate the effects of certain biomass compositional features, including lignin composition, on $\mathrm{AD}$ methane production yields and rates, and to assess whether biomass traits previously identified as potential proxy traits for breeding towards lower EH recalcitrance might also be used for improving $\mathrm{AD}$ performance.

\section{Materials and Methods}

Refer to Fig. 1 for an overview of the experimental procedures. 
Fig. 1 Overview of the experimental procedures

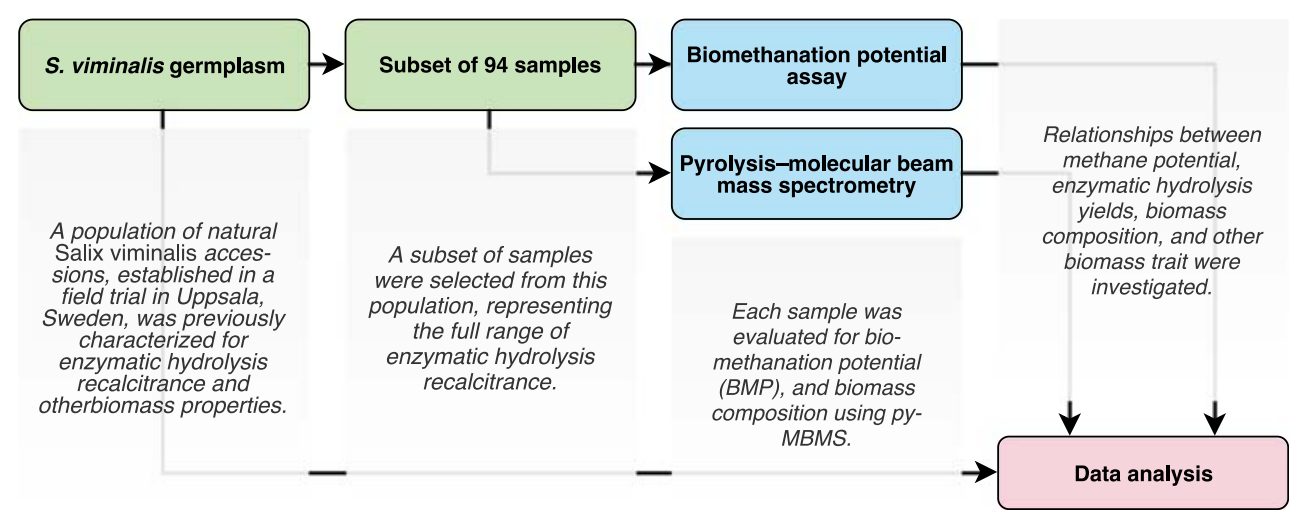

\section{Plant Material}

Plant material for this study consisted of 2-year-old Salix viminalis shoots from a previously described population, consisting of 291 genetically distinct individuals, collected in the wild in Europe and Russia and planted in a randomized complete block experiment in Pustnäs, Uppsala, Sweden $\left(59^{\circ} 48^{\prime} \mathrm{N}, 17^{\circ} 39^{\prime} \mathrm{E}\right)[26]$. EH sugar yields were previously measured as glucose, xylose, and combined glucose + xylose values using a miniaturized high-throughput pretreatment and saccharification assay [27, 28]. A subset of samples from this population ( $n=94$, encompassing 71 distinct genotypes) was chosen such as to reflect the full range of EH recalcitrance, i.e., sugar release values, with the range of values spanning $0.09-0.45 \mathrm{~g} / \mathrm{g}$ dry biomass for combined glucose and xylose release. To ensure fair comparisons, material for this study was prepared in the same manner as when it was characterized for $\mathrm{EH}$ recalcitrance. In brief, the longest shoot of each plant was coarsely chipped using a compost grinder (Viking GE 150, Viking GmbH, Langkampfen, Austria), dried at $60{ }^{\circ} \mathrm{C}$ for 6 hours, and milled using a Wiley Mini-Mill (Thomas Scientific, Swedesboro, NJ, USA) to pass through a 20-mesh sieve. Milled biomass samples were stored in airtight antistatic bags. The biomass properties of interest for this study, previously determined, were fresh weight of the main shoot (MSW), whole plant fresh weight (FW), basal stem diameter (Dia), and wood density (Dens).

\section{Biomethanation Potential Assay}

The BMP assay was conducted using inoculum from a wastewater treatment plant in Uppsala, Sweden. The total solids (TS) and volatile solids (VS) of the inoculum amounted to $2.9 \%$ and $1.9 \%$ of wet weight, respectively. The $\mathrm{pH}$, alkalinity, and ammoniumnitrogen level was 7.0, $6300 \mathrm{mg} \mathrm{HCO}_{3}{ }^{-} / 1$, and $1.2 \mathrm{~g} /$, respectively (values obtained by the biogas plant operator). Ground wood material was analyzed in triplicate, and the trial also included cellulose and inoculum controls, in triplicate. Each treatment contained $50 \mathrm{~g}$ of inoculum, $50 \mathrm{~g}$ of tap water, and $0.3 \mathrm{~g}$ of dry biomass (exact weights recorded) in 309-ml glass bottles, giving an inoculum VS/plant material TS ratio of 3.1:1 and a load of $3 \mathrm{~g}$ $\mathrm{TS} / 1$, in accordance with standard protocols for the BMP assay [29]. Biomass was weighed using an AX204 analytical scale (Mettler-Toledo, Columbus, OH, USA). Bottles were sealed with butyl rubber seals and metal caps and incubated at $37^{\circ} \mathrm{C}$. Sample gas pressures were measured at five occasions using a Greisinger GMH 3111 pressure gauge (GHM Messtechnik GmbH, Regenstauf, Germany) over the total duration of 94 days. Samples were thoroughly mixed by shaking before sampling for gas composition. Gas composition was measured using gas chromatography (GC) as previously described [30].

Normalized gas volumes $(273 \mathrm{~K}, 1 \mathrm{~atm})$ were calculated using the equation

$\mathrm{V}_{\mathrm{N}}=\frac{\mathrm{P} \times \mathrm{V}_{\mathrm{H}} \times \mathrm{T}_{\mathrm{N}}}{\mathrm{P}_{\mathrm{N}} \times \mathrm{T}}$

where $V_{N}$ is the normalized gas volume in $\mathrm{ml}, P$ is the measured pressure in bar, $P_{N}$ is $1 \mathrm{~atm}$ expressed in bar, $V_{H}$ is the headspace volume in $\mathrm{ml}, T_{N}$ is $273 \mathrm{~K}$, and $T$ is the sample temperature $(310 \mathrm{~K})$. Normalized methane values were obtained by multiplying the normalized gas volume by the relative methane content as determined by GC. Gas volumes are expressed as $\mathrm{ml} \mathrm{CH}_{4} / \mathrm{g}$ dry biomass in order to facilitate comparisons with previously obtained sugar release values (expressed as g sugar/g dry biomass).

Methane production rates were calculated according to the following formula

$\Delta \mathrm{n}=\frac{\mathrm{M}_{\mathrm{n}}-\mathrm{M}_{\mathrm{p}}}{\mathrm{n}-\mathrm{p}}$

where $\Delta n$ is the average daily rate of methane production between timepoints $p$ (the preceding timepoint) and $n$, and $M_{n}$ and $M_{p}$ are the cumulative methane productions by timepoints $n$ and $p$.

\section{Pyrolysis-Mass Spectrometry}

To evaluate chemical composition of the samples, each unextracted sample was processed in duplicate using 
pyrolysis - molecular beam mass spectrometry (py-MBMS) according to previously published methods [31]. Helium at a flow rate of $0.9 \mathrm{l} / \mathrm{min}$ was used as the carrier gas, with furnace and interface temperatures of 500 and $350{ }^{\circ} \mathrm{C}$, respectively. Mass-to-charge $(\mathrm{m} / \mathrm{z})$ values were collected from 30-450. Each ion abundance in a spectrum was normalized to the sum of the total ion count for that spectrum.

Influence of spectral components on $\mathrm{AD}$ methane production and EH sugar release was evaluated using two separate methods. In order to assess general influences, Pearson's correlations were calculated for each peak-trait pair.

For elucidating the distinguishing features of very low methane potential samples, outlier samples were defined as having a methane potential lower than $\mathrm{Q}_{1}-1.5 \times \mathrm{IQR}$ (where $Q_{I}$ represents the first quartile of methane potential and IQR is the interquartile range $\left.\left|\mathrm{Q}_{3}-\mathrm{Q}_{1}\right|\right)$. Difference spectra were created by subtracting the mean spectrum of non-outlier samples from the mean spectrum of outlier samples. In the resulting difference spectrum, positive peaks are interpreted as being more abundant in outlier samples, whereas negative peaks are more abundant in non-outlier samples.

\section{Software}

All calculations were performed using $\mathrm{R}$ version 3.5.2 [32]. Data was visualized using the $\mathrm{R}$ packages ggplot 2 version 3.1.0 [33] and corrplot version 0.84 [34].

\section{Results}

\section{Methane Production, Rates, and Potentials}

The BMP assay was concluded after 94 days, and methane production was evaluated at five timepoints during this period (Fig. 2a). Final methane potentials (M94), after subtracting background production, were $198.0 \mathrm{Nml} \mathrm{CH}_{4} /$ g dry biomass ( $18.5 \%$ coefficient of variation, CV), with a range of 28.6-245.9 Nml CH $4 / \mathrm{g}$ dry biomass (Fig. 2a, Table 1). At days 20 and 42, mean accumulated methane production reached $42.0 \%(18.3 \% \mathrm{CV})$ and $73.0 \%$ (10.9\% $\mathrm{CV}$ ) of the final potential, respectively. Accumulated methane production values at days 20-94 (M20-M94) exhibited skewed normal distributions with long left tails, as opposed to the flat distribution of the sugar release values (Fig. 2b, c). Methane potentials at day 5 (M5) were very low and will be disregarded for brevity.

The methane production rates were $5.1 \mathrm{Nml} / \mathrm{g}$ biomass/ day between days 5 and $20(\Delta 20 ; 21.8 \% \mathrm{CV})$, and 2.8 $\mathrm{Nml} / \mathrm{g}$ biomass/day between days 20 and $42(\Delta 42$; $19.2 \% \mathrm{CV}$ ). After day 42, rates were markedly reduced (Fig, 2a; Table 1). Cellulose controls generated 368.2 $(2.8 \% \mathrm{CV}) \mathrm{Nml} \mathrm{CH}_{4} / \mathrm{g} \mathrm{VS}$, indicating a well-functioning inoculum [35], and the methane production of the inoculum controls was $54.0(15.7 \% \mathrm{CV}) \mathrm{Nml} \mathrm{CH}_{4}$.

\section{Correlations Between Methane Production, Biomass Traits, and Sugar Yields}

EH yields correlated strongly with the biomass yield traits whole plant fresh weight (FW), main shoot diameter (Dia), and main shoot weight (MSW; $r=0.65-0.80$; Fig. 3), in line with what was observed in the main population [28]. Correlations between methane production (M20-M94) and these biomass traits were weaker $(r=$ $0.24-0.51)$. Correlations between methane production and sugar release ranged from 0.43 to 0.66 (Fig. 3). Clear distinctions were seen when comparing correlations between sugar release and accumulated methane production at different timepoints (Fig. 3). Sugar release and biomass yield traits were generally moderately strongly correlated with M20 and M42, with weaker correlations observed at the later timepoints. Notably, wood density was equally positively correlated with methane production at all timepoints $(r=0.26-0.29)$.

\section{Py-MBMS Spectral Features}

Py-MBMS spectral features (Fig. 4) exhibited similar correlation patterns for sugar release, early-stage methane production (M20), and early methane rate $(\Delta 20)$, with several peaks indicative of C6 sugars (e.g., $m / z 57,60,73,114$ ) and syringyl lignin $(m / z, 154,167,180,194,208,210)$ being positively correlated with both sugar release and methane production. Negative correlations were found for peaks diagnostic for guaiacyl lignin $(m / z, 124$, but not 137), $p$ coumaric acid/coumaryl (H) lignin $(\mathrm{m} / \mathrm{z}, 120)$, and ferulic acid ( $\mathrm{m} / \mathrm{z} 150$ and 164, also derived from G lignin). Peaks at $m / z, 272,302$, and 332, suggested to be indicative of lignin dimers of increasing degree of methoxylation (e.g., G-G, G-S, and S-S dimers, respectively) [36], were correlated with conversion yields according to degree of methoxylation, with $\mathrm{m} / \mathrm{z} 272$ (consistent with guaiacyl monomers) being negatively and $\mathrm{m} / \mathrm{z} 332$ (consistent with syringyl monomers) positively correlated with yields under both systems. Negative correlations were also found for several peaks indicative of phenolic compounds $(\mathrm{m} / \mathrm{z} 81$, $91,92,94,107,110)$. These peaks are not otherwised annotated due to their ambiguous and multiple sourcing and are highly overlapping with all lignin-based phenolics, some sugars, and secondary metabolites, and thus not necessarily attributable to the presence of an individual biopolymer or component. Notably, peaks indicative of $\mathrm{C} 5$ sugars (e.g., $\mathrm{m} /$ $z 85,114)$ were often neutral for final methane potential, while being positively correlated with sugar release and with early methane production and rate (M20, $\Delta 20)$. 
a

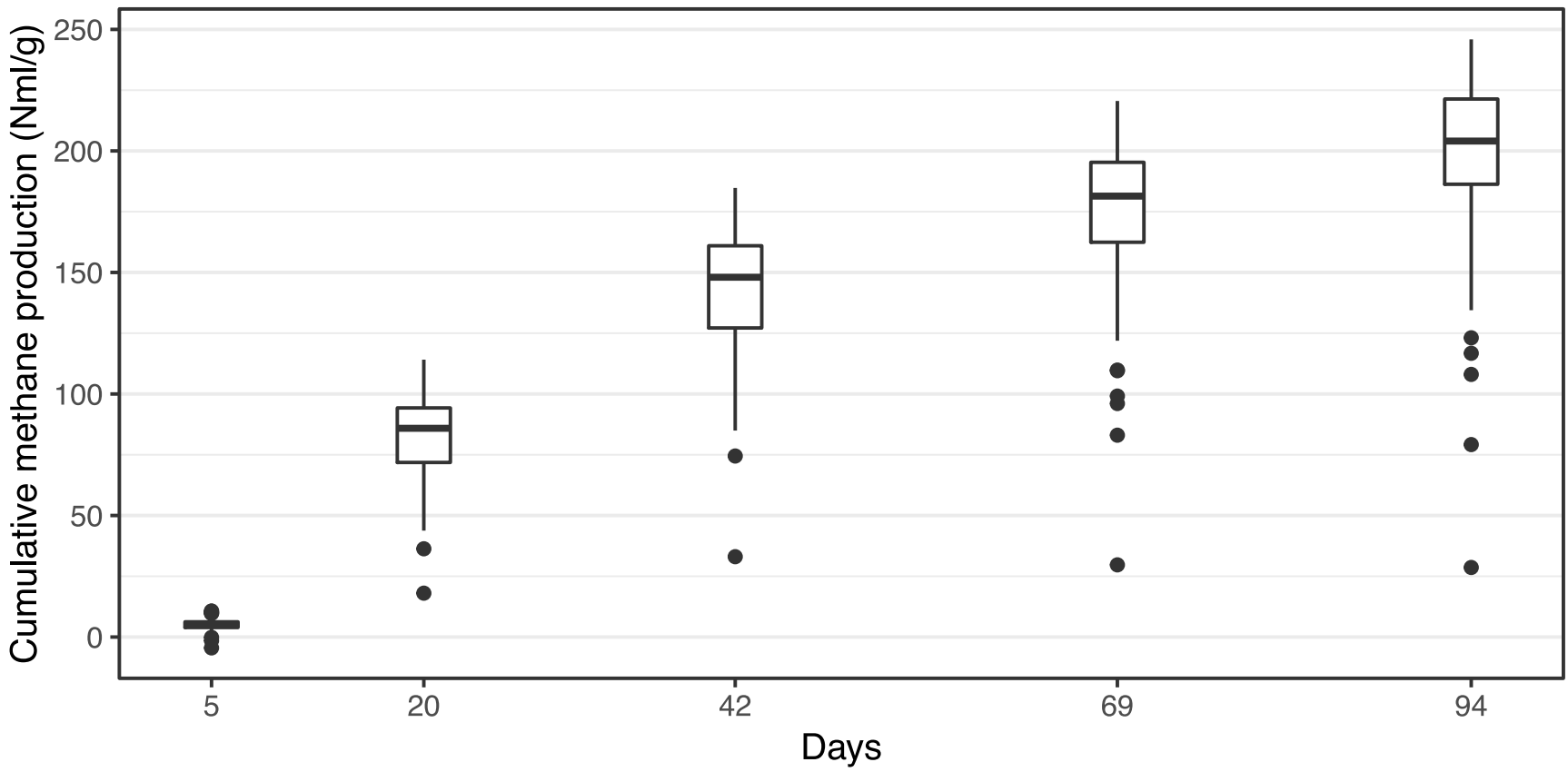

b

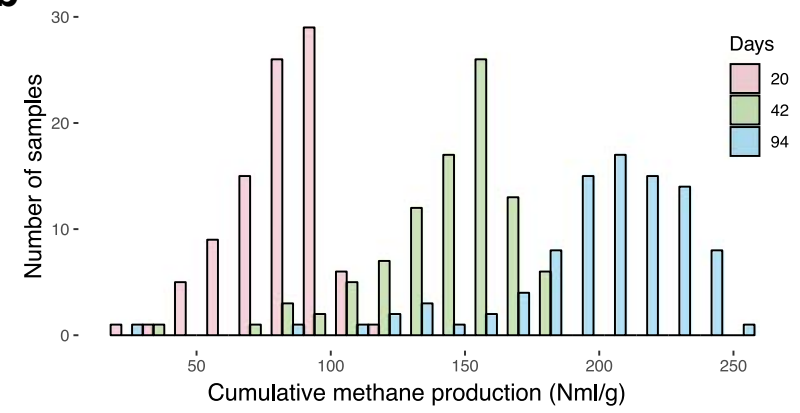

Fig. 2 a Cumulative methane production ( $\mathrm{Nml} \mathrm{CH}_{4} / \mathrm{g}$ biomass). Top and bottom edges of boxes indicate third and first quartile, respectively. Whiskers extend at most 1.5 IQR and dots indicate outliers. b

Difference spectra, constructed by subtracting mean pyrolysis mass spectra of one group of samples from another, were used to investigate characteristics distinguishing low methane potential outliers from the mean (Fig. 5). The outlier samples (see Methods section) with low BMP were found to produce lower amounts of
C

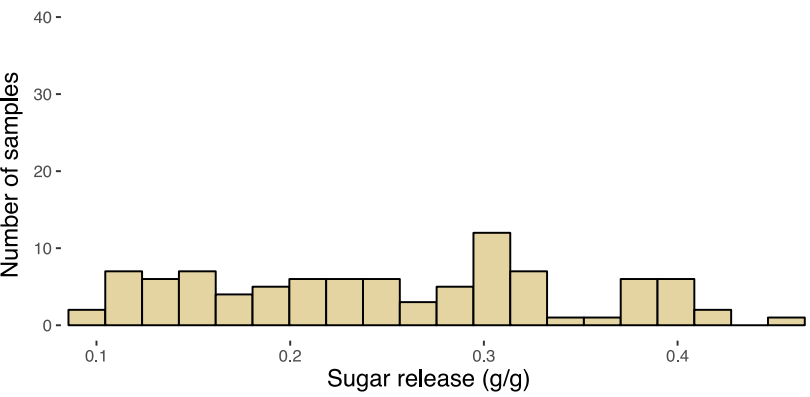

Histogram showing distribution of methane production at timepoints 20, 42, and 94 days. c Histogram showing distribution of sugar release values

$\mathrm{S}$ lignin-derived ions, higher amounts of $\mathrm{G}$ lignin or ferulic acid-derived ions (particularly $\mathrm{m} / \mathrm{z}, 164$ ), and lower amounts of carbohydrate-derived ions compared to the average sample. However, these samples were also found to contain higher amounts of peaks with $\mathrm{m} / \mathrm{z}$ values of 81, 91, 94, 107, and 110, discussed above.
Table 1 Descriptive statistics for methane production and rates at each timepoint

\begin{tabular}{lllllllll}
\hline $\begin{array}{l}\text { Days } \\
\text { elapsed }\end{array}$ & $\begin{array}{l}\text { Methane } \\
\text { production } \\
(\mathrm{Nml} \mathrm{CH} / \mathrm{g})\end{array}$ & $\begin{array}{l} \pm \mathrm{CV} \\
(\%)\end{array}$ & $\begin{array}{l}\text { Methane } \\
\text { content } \\
(\%)\end{array}$ & $\begin{array}{l} \pm \mathrm{CV} \\
(\%)\end{array}$ & $\begin{array}{l}\mathrm{Rate}^{\mathrm{a}} \\
(\mathrm{Nml} \mathrm{CH} / \\
\mathrm{g} / \text { day })\end{array}$ & $\begin{array}{l} \pm \mathrm{CV} \\
(\%)\end{array}$ & $\begin{array}{l}\text { Percentage of } \\
\text { final potential } \\
(\%)\end{array}$ & $\begin{array}{l} \pm \mathrm{CV} \\
(\%)\end{array}$ \\
\hline 5 & 5.1 & 45.2 & 6.5 & 20.3 & 1.0 & 45.2 & 2.4 & 91.8 \\
20 & 82.1 & 21.3 & 29.0 & 5.7 & 5.1 & 21.8 & 42.0 & 18.3 \\
42 & 143.1 & 18.3 & 38.7 & 4.7 & 2.8 & 19.2 & 73.0 & 10.9 \\
69 & 175.1 & 18.5 & 43.9 & 3.8 & 1.2 & 26.3 & 88.7 & 5.1 \\
94 & 198.0 & 18.5 & 45.9 & 4.6 & 0.9 & 37.7 & 100.0 & 0.0 \\
\hline
\end{tabular}

${ }^{\mathrm{a}}$ The rate reflects the average rate of methane production during each period beginning at the previous timepoint 
Fig. 3 Pearson's correlations, significant at the $p<0.001$ level, of $\mathrm{EH}$ and $\mathrm{AD}$ yields and biomass traits. Legend: M20-M94, methane production at days 20 94; $\Delta 20-\Delta 94$, methane production rates at days $20-94$; Glu, glucose release; Xyl, xylose release; $\mathrm{G}+\mathrm{X}$, glucose + xylose release; $\mathrm{S} / \mathrm{G}, \mathrm{S} / \mathrm{G}$ ratio; Dia, main shoot diameter; MSW, main shoot weight; FW, whole plant fresh weight; Dens, wood density

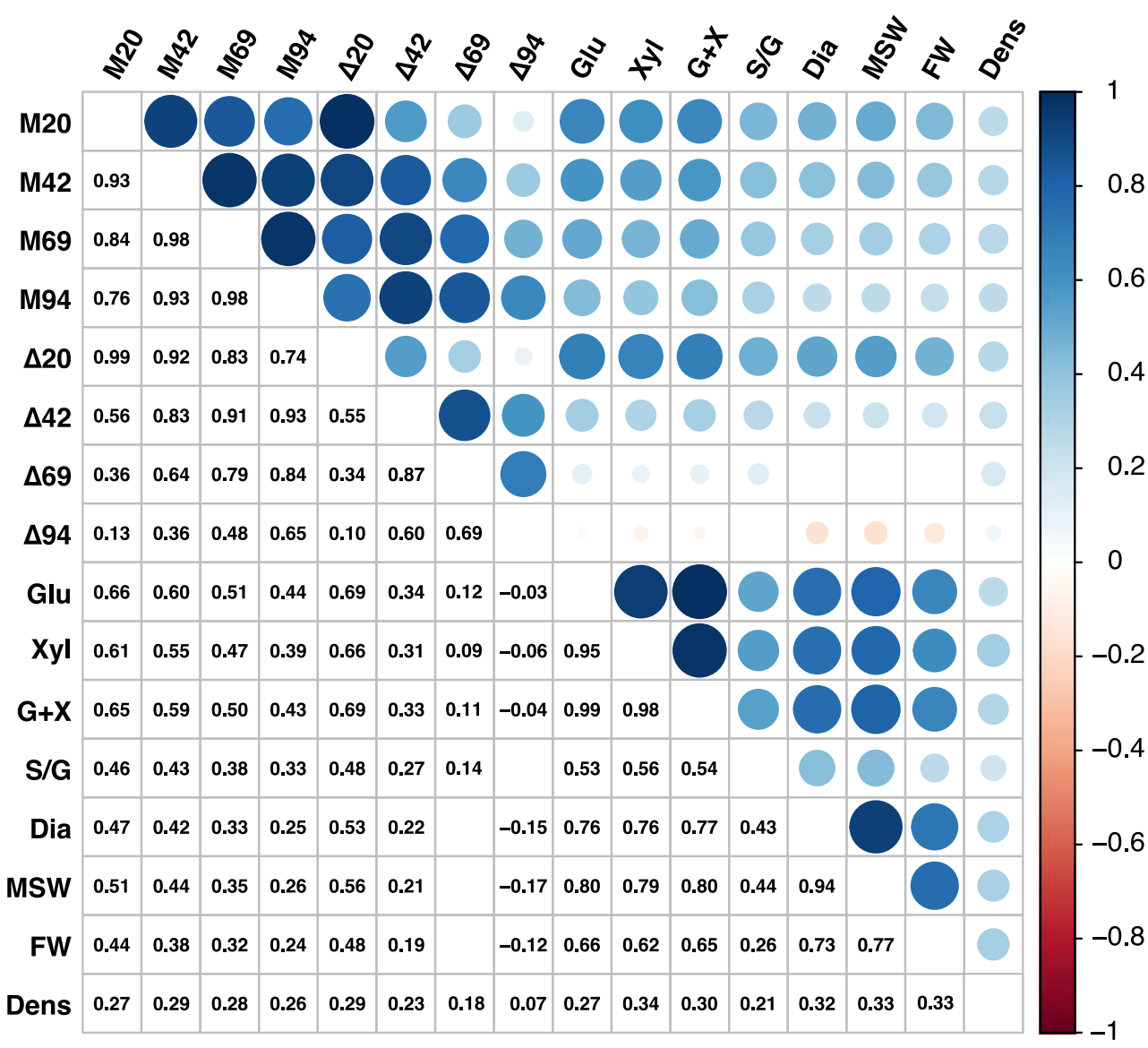

\section{Discussion}

\section{Anerobic Digestion Performance and Relation to Enzymatic Hydrolysis Yields}

Whereas recalcitrance under the EH paradigm primarily relates to yields, e.g., amount sugar released per g biomass, recalcitrance under the $\mathrm{AD}$ paradigm is clearly a more complex phenotype, encompassing both yields and rates. For woody biomass, which is degraded slowly in the AD process [37], initial conversion rates may be a more important measure than final methane potentials, due to the retention time of the typical AD process being less than what is required for complete degradation of the material. EH yields were positively correlated with methane production, driven by the conversion of carbohydrate to methane during the early stages of

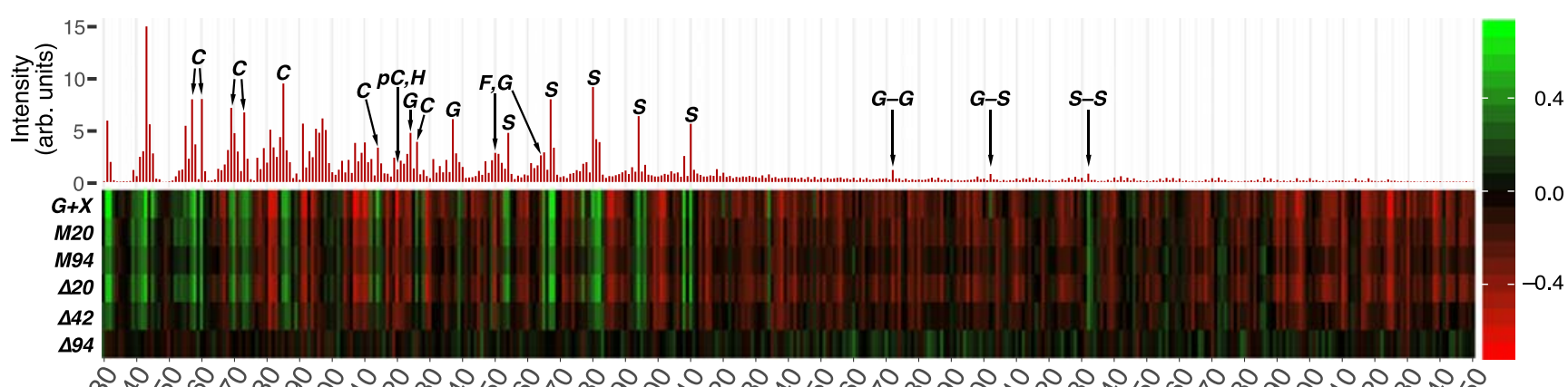

भेष

\section{$m / z$}

Fig. 4 Mean spectrogram of peaks with $m / z$ values 30-450. Certain peaks are marked by origin: carbohydrate $(\mathrm{C})$, guaiacyl lignin $(\mathrm{G})$, syringyl lignin (S), $p$-coumaric acid (pC; also from $\mathrm{H}$ lignin), ferulic acid ( $\mathrm{F}$; also from $\mathrm{G}$ lignin), and tentatively assigned lignin dimers ( $\mathrm{G}-\mathrm{G}, \mathrm{G}-\mathrm{S}$, and S-S). The heatmap shows each peak's Pearson's correlation coefficient (indicated by the legend) for the traits glucose + xylose release $(\mathrm{G}+\mathrm{X})$, methane production at 20 days (M20), methane production at 94 days (M94), and daily rate of methane production at day 20,42 , and $94(\Delta 20-\Delta 94)$. 




Fig. 5 Difference spectrum, showing the $m / z$ range 30-250, of the five outlier low BMP samples vs all other samples. Certain peaks, indicative of phenolic compounds but not otherwise annotated due to ambiguous and multiple sourcing, are marked in red.

the process. For glucose release, the correlation coefficient was 0.69 when comparing EH yields with average methane production rate between days 5 and $20(\Delta 20)$, although the correlation strength deteriorated quickly during the process, becoming -0.03 for late stage rates $(\Delta 94)$. The same pattern of diminishing correlation strength was seen for carbohydratederived py-MBMS peaks. On the other hand, many spectral features of high $\mathrm{m} / \mathrm{z}$ were mostly weakly negatively correlated with early and mid-stage methane production and rates and with EH yields but positively correlated with late-stage methane production rates (Fig. 4). This indicates that carbohydrate polymer recalcitrance determines the conversion rate during the early stages, but that other biomass components play a larger role later in the process. Taken together, these findings suggest that $\mathrm{EH}$ yields and initial $\mathrm{AD}$ rates and yields are influenced by the same structural and compositional recalcitrance features, whereas at the later stage of $\mathrm{AD}$, other factors, perhaps related to ultrastructural features of the biomass or to the level and character of non-carbohydrate substrate components, dictate degradation performance.

Interestingly, although the samples used for the present study represented the full spectrum of sugar release from very low to very high, methane production rather exhibited a skewed normal distribution with several outliers (Fig. 2b, c). Excluding the outliers (i.e., the five lowest BMP samples at day 94, discussed below), the highest producing samples had less than a twofold increase of methane potential over the lowest samples, whereas the range for sugar release spanned almost fivefolds from lowest to highest. This finding is likely indicative of the great degrading capacity of the AD consortium, combined with its metabolic versatility (i.e., its ability to utilize compounds other than sugars).

Although the BMP test is a standard method, its results can vary depending on several parameters including inoculum source, inoculum/substrate ratio, incubation conditions, and duration [29], which affect how thoroughly the substrate can be decomposed. Accordingly, the deterioration of correlation strength between $\mathrm{EH}$ and $\mathrm{AD}$ yields over time suggests that the degree of substrate degradation is an important confounder when comparing EH and AD using the BMP test. Thus, it follows that if a BMP test is performed using conditions that allow a more thorough decomposition of the feedstock, the results are less likely to correlate well with EH sugar yields. Although a complex issue, this may offer an explanation for the inconsistent results reported in the literature.

BMP values for the material in this study averaged 198.0 $\mathrm{Nml} \mathrm{CH} / \mathrm{g}$ biomass, with the highest BMP samples yielding almost $250 \mathrm{Nml} \mathrm{CH}_{4} / \mathrm{g}$. A similar maximum value, albeit with a slightly lower mean of $149.7 \mathrm{Nml} \mathrm{CH}_{4} / \mathrm{g} \mathrm{VS}$, was found by Pawar et al. [38], using non-pretreated Salix milled to the approximate particle size of the present study and using continuous stirring during incubation. Slightly higher values (mean 250, maximum $320 \mathrm{Nml} \mathrm{CH}_{4} / \mathrm{g}$ VS) were found in a study evaluating several Salix and Populus species [37]. Although comparisons between BMP values found in literature are complicated due to variations in methodology, taken together, the results of the aforementioned studies and the present one suggest that the BMP of high-performing Salix clones is at least $250 \mathrm{Nml} \mathrm{CH}_{4} / \mathrm{g}$. It is worth noting that the BMP of steam pretreated Salix can be in excess of $400 \mathrm{Nml}$ $\mathrm{CH}_{4} / \mathrm{g}$ VS [21].

\section{Influence of Lignin Composition}

Certain lignin compositional factors could be attributed to positive and negative influences on both $\mathrm{EH}$ and $\mathrm{AD}$. S lignin-derived py-MBMS ions were relatively strongly associated with EH yields in the positive direction and displayed 
similar correlations with early AD methane production and rate (M20 and $\Delta 20$ ). Similarly, py-MBMS peaks derived from $\mathrm{G}, \mathrm{H}$, and $p$-coumaric acid lignin were negatively correlated with EH yields as well as with methane production and rates, again primarily during the early stage. Peaks at $\mathrm{m} / \mathrm{z}, 150$ and 164, which may be attributed to either $\mathrm{G}$ lignin or ferulic acid, negatively correlated with yields under both systems but were more strongly correlated with methane production and rates than EH yields, an uncommon finding in this dataset. This finding suggests that either ferulic acid, a lignin moiety linked to increased recalcitrance [39], or guaiacyl moieties, when incorporated into lignin, create structures that are either especially recalcitrant to the $\mathrm{AD}$ process or that are facilitated by hydrothermal pretreatment in their degradation.

Py-MBMS peaks of $m / z, 272,302$, and 332 were correlated with both EH and AD yields. These peaks have previously been ascribed to dimeric, possibly stilbene-type, lignin structures of increasing methoxylation (i.e., 272 represents a $\mathrm{G}-\mathrm{G}$ dimer whereas 332 represents an S-S dimer; see [40] for a more in-depth discussion). The direction of the observed correlations was dependent on the degree of methoxylation, with $\mathrm{m} / \mathrm{z} 272$ being negatively and $\mathrm{m} / \mathrm{z} 332$ positively correlated with yields under both systems, consistent with the corresponding monomers' correlations with AD/BMP. Although the structures of the sources of these ions are still hypothetical, it is quite possible that the presence of the peaks 272 and 332 emerges from linkage patterns within the lignin polymer that are especially important to recalcitrance; however, more data would be required to ascertain whether this is the case.

Although lignin S/G ratio has been shown to impact the susceptibility of biomass to certain pretreatments, its influence as reported in the literature is highly variable. Moreover, only a few studies have evaluated the influence of $\mathrm{S} / \mathrm{G}$ ratio on nonpretreated biomass and on $\mathrm{AD}$ performance. In several studies, S/G ratio has been demonstrated to be negatively correlated with EH yields of untreated material [41, 42]. On the other hand, in a study using organosolv, kraft, and synthetic lignins as well as lignosulfonate, Barakat et al. [43] found that the main predictor of lignin degradability under $A D$ was the $\mathrm{S} / \mathrm{G}$ ratio, which exhibited a strong positive correlation. Similarly, it was found that $\mathrm{AD}$ degradation of birch hydrolysis lignin drastically reduced the $S / G$ ratio of the material, indicating preferential degradation of syringyl units [44]. Positive correlations between $\mathrm{S} / \mathrm{G}$ ratio and $\mathrm{AD}$ performance in degradation of lignocellulosic materials have generally been reported, for example, in Populus biomass using C. thermocellum [45], in $\mathrm{AD}$ of herbaceous material [46], as well as in the present study. However, in a study on non-pretreated Salix, evaluating correlations between methane potentials and rates and FT-IR spectral features [38], some G lignin-assigned wavenumbers were positively correlated with both potentials and rates, although this finding was confounded by positive correlations between these wavenumbers and carbohydrate content. Taken together, the results may point to a difference in the effect of S/ $G$ ratio on deconstruction of non-pretreated material that is dependent on the origin of the cellulolytic enzymes (fungal vs. bacterial).

\section{Presence of Inhibitory Substances in Biomass}

A possibly confounding factor when sugar release and methane production are used as markers for biomass recalcitrance is the presence of inhibitors. Although purely enzymatic systems can indeed be sensitive to certain inhibitors (e.g., see [47]), an AD microbial consortium may present further targets of inhibition due to requiring a functioning metabolism and cooperation between its diverse microbial members (see [48] for a review on the subject). To assess whether the several low BMP outlier samples (Fig. 1a) observed in this study contained inhibitors compromising the function of the $\mathrm{AD}$ consortium, these samples were compared against all other samples using a py-MBMS difference spectrum, revealing several distinct features (Fig. 5). Low BMP outlier samples were lower in carbohydrate and S lignin and had markedly higher levels of $\mathrm{G}$ lignin and ferulic acid-derived ions, as would be expected for more recalcitrant samples. However, several less diagnostic peaks were also more abundant in outlier samples: peaks at $m / z 81,91,92,94,107$, and 110 . These peaks are indicative of phenolic compounds, although their original sources, from biopolymers, metabolites, or otherwise, are not clear as they likely represent fragments/rearrangements formed from pyrolysis of many lignin, other phenolic-derived species, or even sugars to some degree. Nonetheless, the increased production of these ions from the low BMP outliers does not necessarily correlate with increased abundance of other lignin-derived ions. Therefore, the source of these ions may be more closely related to the presence of phenolic metabolites, although future studies would be needed to elucidate the metabolomic profiles of this population to make such a correlation and extend it to BMP and sugar release potential.

Many phenolic compounds have been shown to be inhibitory to the AD process $[49,50]$, and the nature of these compounds may merit further study. Phenolic metabolites are commonly found in bark of species from the Salicaceae family, as demonstrated in the commercial willow hybrid Karin [51], in S. hulteni [52], and in several Salix and Populus spp. $[53,54]$. The types and levels of secondary metabolites differ widely between species, vary according to season [54], and are heritable with significant genotype $\times$ environment effects [55]. Given that larger shoots contain relatively less bark and that shoot weight was only weakly correlated with methane potential, it is most likely that bark composition, not proportion, dictates its influence on $\mathrm{AD}$ performance, highlighting the importance of clone choice for use of Salix as feedstock for AD. In this study, the material used originated from a study population consisting of material of similar age which was 
harvested at the same time. Thus, the differences observed would be primarily due to genotype or genotype $\times$ environment, although purely environmental influences cannot be entirely ruled out.

\section{Implications for Breeding}

Biomass yield traits (shoot weight and diameter) and lignin S/G ratio were previously identified as potential proxy traits for $\mathrm{EH}$ sugar release screening in recurrent selection breeding programs in S. viminalis, in a characterization of the current study population [28]. Here, we find the same to hold true for methane production in this population subset, primarily driven by early methane production rates, with attenuation at the later stages. The same pattern of attenuated correlations was observed for all methane production/biomass trait pairs except for wood density (Fig. 3). As there were also strong correlations between early methane conversion rates and sugar release, breeding for reduced $\mathrm{EH}$ recalcitrance will benefit $\mathrm{AD}$ primarily through increased initial conversion rates, arguably the most important measure of recalcitrance for woody material in AD. Natural populations of Salix harbor variation that can be used for breeding towards this goal. However, it is likely that the relative improvements in $\mathrm{AD}$ performance from an $\mathrm{EH}-$ focused breeding program will be smaller than those for $\mathrm{EH}$ itself. Moreover, the presence of secondary metabolites acting as inhibitors of the $\mathrm{AD}$ process should be taken into account during the breeding process. Given that the presence of many secondary metabolites may confer other desirable traits, such as herbivore deterrence, it is warranted to more closely evaluate the influence of specific metabolites on the $\mathrm{AD}$ process to tailor breeding programs towards biorefinery-use varieties.

\section{Conclusions}

In this study of biomass recalcitrance in Salix viminalis under two separate biological conversion paradigms, enzymatic hydrolysis and anaerobic digestion, we find that reducing recalcitrance towards enzymatic hydrolysis is likely to translate to improved performance under anaerobic digestion, primarily manifested as higher early conversion rates. Early conversion rates were positively correlated with lignin $\mathrm{S} / \mathrm{G}$ ratio, a parameter that was found to positively affect enzymatic hydrolysis yields in this population, and with other biomass traits previously identified as possible proxy traits for breeding towards reduced enzymatic hydrolysis recalcitrance. Furthermore, pyMBMS difference spectra highlighted several important peaks and spectral patterns with negative influence on AD degradation, warranting further investigation.

Acknowledgments The authors wish to thank Simon Isaksson for assistance with setting up the BMP assay.
Availability of Data and Material All data is available on request.

Author's Contributions JAO, MS, and AS conceived of and designed the study. JAO performed the BMP assay. AEHW ran the py-MBMS assay and assisted in the interpretation of the results. JAO analyzed and compiled the data and wrote the bulk of the manuscript. All authors provided feedback on the manuscript.

Funding Information Open access funding provided by Swedish University of Agricultural Sciences. This study was performed within the research project OPTUS, which is financed by the Swedish Research Council for Environment, Agricultural Sciences and Spatial Planning (Formas) under project number 2016-20031. Additional funding was provided by the StandUp for Energy program.

This work was authored in part by Alliance for Sustainable Energy, LLC, the manager and operator of the National Renewable Energy Laboratory for the US Department of Energy (DOE) under Contract No. DE-AC36-08GO28308. Support at NREL was provided in part by the BioEnergy Science Center (BESC) and the Center for Bioenergy Innovation (CBI) from the US Department of Energy Bioenergy Research Centers (BER) supported by the Office of Biological and Environmental Research in the DOE Office of Science. The views expressed in the article do not necessarily represent the views of the DOE or the US Government. The US Government retains and the publisher, by accepting the article for publication, acknowledges that the US Government retains a nonexclusive, paid-up, irrevocable, worldwide license to publish or reproduce the published form of this work or allows others to do so, for US Government purposes.

\section{Compliance with Ethical Standards}

Competing Interests The authors declare no competing interests.

Abbreviations $\Delta n$, Average daily rate of methane evolution between timepoint $n$ and the preceding timepoint (e.g., $\Delta 20$ is the average rate between timepoints 5 and 20); $A D$, Anaerobic digestion; $B M P$, Biomethanation potential; $C V$, Coefficient of variation; Dens, Wood density; Dia, Stem diameter; $E H$, Enzymatic hydrolysis; $F W$, Fresh weight of whole plant; $G C$, Gas chromatography; $M n$, Cumulative methane production by day $n ; M S W$, Main shoot weight; $P y-M B M S$, Pyrolysis-molecular beam mass spectrometry; $S / G$ ratio, Syringyl/guaiacyl ratio in lignin polymer; TS, Total solids; VS, Volatile solids

Open Access This article is distributed under the terms of the Creative Commons Attribution 4.0 International License (http:// creativecommons.org/licenses/by/4.0/), which permits unrestricted use, distribution, and reproduction in any medium, provided you give appropriate credit to the original author(s) and the source, provide a link to the Creative Commons license, and indicate if changes were made.

\section{References}

1. Ragauskas AJ, Williams CK, Davison BH, Britovsek G, Cairney J, Eckert CA, Frederick WJ, Hallett JP, Leak DJ, Liotta CL, Mielenz JR, Murphy R, Templer R, Tschaplinski T (2006) The path forward for biofuels and biomaterials. Science 311(5760):484-489. https:// doi.org/10.1126/science. 1114736

2. Haberl H, Erb K-H, Krausmann F, Running S, Searchinger TD, Smith WK (2013) Bioenergy: how much can we expect for 2050 ? Environ Res Lett 8(3):031004. https://doi.org/10.1088/1748-9326/ $8 / 3 / 031004$ 
3. Himmel ME, Ding S-Y, Johnson DK, Adney WS, Nimlos MR, Brady JW, Foust TD (2007) Biomass recalcitrance: engineering plants and enzymes for biofuels production. Science 315(5813): 804-807. https://doi.org/10.1126/science.1137016

4. McCann MC, Carpita NC (2015) Biomass recalcitrance: a multiscale, multi-factor, and conversion-specific property. J Exp Bot 66(14):4109-4118. https://doi.org/10.1093/jxb/erv267

5. Meng X, Ragauskas AJ (2014) Recent advances in understanding the role of cellulose accessibility in enzymatic hydrolysis of lignocellulosic substrates. Curr Opin Biotechnol 27:150-158. https://doi. org/10.1016/j.copbio.2014.01.014

6. Weimer PJ, Russell JB, Muck RE (2009) Lessons from the cow: what the ruminant animal can teach us about consolidated bioprocessing of cellulosic biomass. Bioresour Technol 100(21): 5323-5331. https://doi.org/10.1016/j.biortech.2009.04.075

7. Lynd LR, Liang X, Biddy MJ, Allee A, Cai H, Foust T, Himmel ME, Laser MS, Wang M, Wyman CE (2017) Cellulosic ethanol: status and innovation. Curr Opin Biotechnol 45:202-211. https:// doi.org/10.1016/j.copbio.2017.03.008

8. Bayer EA, Lamed R, Himmel ME (2007) The potential of cellulases and cellulosomes for cellulosic waste management. Curr Opin Biotechnol 18(3):237-245. https://doi.org/10.1016/j.copbio.2007. 04.004

9. Schnürer A (2016) Biogas production: microbiology and technology. Adv Biochem Eng Biotechnol 156:195-234. https://doi.org/10. 1007/10 20165

10. Lynd LR, Weimer PJ, van Zyl WH, Pretorius IS (2002) Microbial cellulose utilization: fundamentals and biotechnology. Microbiol Mol Biol Rev 66(3):506-577. https://doi.org/10.1128/MMBR.66. 3.506-577.2002

11. Guo M, Song W, Buhain J (2015) Bioenergy and biofuels: history, status, and perspective. Renew Sust Energ Rev 42:712-725. https:// doi.org/10.1016/j.rser.2014.10.013

12. Scarlat N, Dallemand J-F, Fahl F (2018) Biogas: developments and perspectives in Europe. Renew Energy 129:457-472. https://doi. org/10.1016/j.renene.2018.03.006

13. Agler MT, Wrenn BA, Zinder SH, Angenent LT (2011) Waste to bioproduct conversion with undefined mixed cultures: the carboxylate platform. Trends Biotechnol 29(2):70-78. https://doi.org/10. 1016/j.tibtech.2010.11.006

14. López JC, Arnáiz E, Merchán L, Lebrero R, Muñoz R (2018) Biogas-based polyhydroxyalkanoates production by Methylocystis hirsuta: a step further in anaerobic digestion biorefineries. Chem Eng J 333:529-536. https://doi.org/10.1016/j.cej.2017.09.185

15. Kleerebezem R, Joosse B, Rozendal R, Van Loosdrecht MCM (2015) Anaerobic digestion without biogas? Rev Environ Sci Biotechnol 14(4):787-801. https://doi.org/10.1007/s11157-0159374-6

16. Moscoviz R, Trably E, Bernet N, Carrère H (2018) The environmental biorefinery: state-of-the-art on the production of hydrogen and value-added biomolecules in mixed-culture fermentation. Green Chem 20(14):3159-3179. https://doi.org/10.1039/ C8GC00572A

17. Monlau F, Barakat A, Trably E, Dumas C, Steyer J-P, Carrère H (2013) Lignocellulosic materials into biohydrogen and biomethane: impact of structural features and pretreatment. Crit Rev Environ Sci Technol 43(3):260-322. https://doi.org/10.1080/10643389.2011. 604258

18. Monlau F, Sambusiti C, Ficara E, Aboulkas A, Barakat A, Carrère H (2015) New opportunities for agricultural digestate valorization: current situation and perspectives. Energy Environ Sci 8(9):26002621. https://doi.org/10.1039/C5EE01633A

19. Liebetrau J, Reinelt T, Agostini A, Linke B (2017) Methane emissions from biogas plants. Methods for measurement, results and effect on greenhouse gas balance of electricity produced. IEA Bioenergy Task 37.
20. Frydendal Nielsen S, Jørgensen U, Hjorth M, Felby C, Gislum R (2017) Comparing methods for measuring the digestibility of miscanthus in bioethanol or biogas processing. GCB Bioenergy 9(1):168-175. https://doi.org/10.1111/gcbb.12377

21. Horn SJ, Estevez MM, Nielsen HK, Linjordet R, Eijsink VGH (2011) Biogas production and saccharification of Salix pretreated at different steam explosion conditions. Bioresour Technol 102(17): 7932-7936. https://doi.org/10.1016/j.biortech.2011.06.042

22. Liew LN, Shi J, Li Y (2012) Methane production from solid-state anaerobic digestion of lignocellulosic biomass. Biomass Bioenergy 46:125-132. https://doi.org/10.1016/j.biombioe.2012.09.014

23. Liu X, Bayard R, Benbelkacem H, Buffière P, Gourdon R (2015) Evaluation of the correlations between biodegradability of lignocellulosic feedstocks in anaerobic digestion process and their biochemical characteristics. Biomass Bioenergy 81:534-543. https://doi. org/10.1016/j.biombioe.2015.06.021

24. Holwerda EK, Worthen RS, Kothari N, Lasky RC, Davison BH, Fu C, Wang Z-Y, Dixon RA, Biswal AK, Mohnen D, Nelson RS, Baxter HL, Mazarei M, Muchero W, Tuskan GA, Cai CM, Gjersing EE, Davis MF, Himmel ME, Wyman CE, Gilna P, Lynd LR (2019) Multiple levers for overcoming the recalcitrance of lignocellulosic biomass. Biotechnology for Biofuels 12(1):15. https:// doi.org/10.1186/s13068-019-1353-7

25. Thomas VA, Kothari N, Bhagia S, Akinosho H, Li M, Pu Y, Yoo CG, Pattathil S, Hahn MG, Raguaskas AJ, Wyman CE, Kumar R (2017) Comparative evaluation of Populus variants total sugar release and structural features following pretreatment and digestion by two distinct biological systems. Biotechnology for Biofuels 10(1):292. https://doi.org/10.1186/s13068-017-0975-x

26. Berlin S, Trybush SO, Fogelqvist J, Gyllenstrand N, Hallingbäck HR, Åhman I, Nordh N-E, Shield I, Powers SJ, Weih M, Lagercrantz U, Rönnberg-Wästljung A-C, Karp A, Hanley SJ (2014) Genetic diversity, population structure and phenotypic variation in European Salix viminalis L. (Salicaceae). Tree Genet Genomes 10(6):1595-1610. https://doi.org/10.1007/s11295-0140782-5

27. Decker SR, Sykes RW, Turner GB, Lupoi JS, Doepkke C, Tucker MP, Schuster LA, Mazza K, Himmel ME, Davis MF, Gjersing E (2015) High-throughput screening of recalcitrance variations in lignocellulosic biomass: total lignin, lignin monomers, and enzymatic sugar release. JoVE (Journal of Visualized Experiments) 103: e53163-e53163. https://doi.org/10.3791/53163

28. Ohlsson JA, Hallingbäck HR, Jebrane M, Harman-Ware AE, Shollenberger T, Decker SR, Sandgren M, Rönnberg-Wästljung A-C (2019) Genetic variation of biomass recalcitrance in a natural Salix viminalis (L.) population. Biotechnol Biofuels 12(1):135. https://doi.org/10.1186/s13068-019-1479-7

29. Schnürer A, Bohn I, Moestedt J (2016) Protocol for start-up and operation of CSTR biogas processes. vol 44, vol Suppl. Springer, Berlin, Heidelberg, Berlin, Heidelberg, pp 171-200. doi:https://doi. org/10.1007/8623_2016_214

30. Westerholm M, Roos S, Schnürer A (2010) Syntrophaceticus schinkii gen. nov., sp. nov., an anaerobic, syntrophic acetateoxidizing bacterium isolated from a mesophilic anaerobic filter. FEMS Microbiol Lett 309(1):100-104. https://doi.org/10.1111/j. 1574-6968.2010.02023.x

31. Sykes R, Yung M, Novaes E, Kirst M, Peter G, Davis M (2009) High-throughput screening of plant cell-wall composition using pyrolysis molecular beam mass spectroscopy. In: Mielenz JR (ed) Biofuels: Methods and Protocols, vol 581. Humana Press, Totowa, pp 169-183. https://doi.org/10.1007/978-1-60761-214-8_12

32. R Core Team (2018) R: A language and environment for statistical computing. R Foundation for Statistical Computing, Vienna

33. Wickham H (2009) ggplot2: elegant graphics for data analysis. Springer-Verlag, New York 
34. Wei T, Simko V (2017) R package "corrplot": visualization of a correlation matrix.

35. Holliger C, Alves M, Andrade D, Angelidaki I, Astals S, Baier U, Bougrier C, Buffière P, Carballa M, de Wilde V, Ebertseder F, Fernández B, Ficara E, Fotidis I, Frigon J-C, de Laclos HF, Ghasimi DSM, Hack G, Hartel M, Heerenklage J, Horvath IS, Jenicek P, Koch K, Krautwald J, Lizasoain J, Liu J, Mosberger L, Nistor M, Oechsner H, Oliveira JV, Paterson M, Pauss A, Pommier S, Porqueddu I, Raposo F, Ribeiro T, Rüsch Pfund F, Strömberg S, Torrijos M, van Eekert M, van Lier J, Wedwitschka H, Wierinck I (2016) Towards a standardization of biomethane potential tests. Water Sci Technol 74(11):2515-2522. https://doi.org/10.2166/wst. 2016.336

36. Evans RJ, Milne TA, Soltys MN (1986) Direct mass-spectrometric studies of the pyrolysis of carbonaceous fuels: III. Primary pyrolysis of lignin. J Anal Appl Pyrolysis 9(3):207-236. https://doi.org/10. 1016/0165-2370(86)80012-2

37. Turick CE, Peck MW, Chynoweth DP, Jerger DE, White EH, Zsuffa L, Andy Kenney W (1991) Methane fermentation of woody biomass. Bioresour Technol 37(2):141-147. https://doi.org/10. 1016/0960-8524(91)90202-U

38. Pawar PM-A, Schnürer A, Mellerowicz EJ, Rönnberg Wästljung AC (2018) QTL mapping of wood FT-IR chemotypes shows promise for improving biofuel potential in short rotation coppice willow (Salix spp.). BioEnergy Res 169 (2):1-13. doi:https://doi.org/10. 1007/s12155-018-9901-8

39. de Oliveira DM, Finger-Teixeira A, Rodrigues Mota T, Salvador VH, Moreira-Vilar FC, Correa Molinari HB, Craig Mitchell RA, Marchiosi R, Ferrarese-Filho O, Dantas dos Santos W (2014) Ferulic acid: a key component in grass lignocellulose recalcitrance to hydrolysis. Plant Biotechnol J 13(9):1224-1232. https://doi.org/ 10.1111/pbi.12292

40. Hempfling R, Schulten HR (1990) Chemical characterization of the organic matter in forest soils by Curie point pyrolysis-GC/MS and pyrolysis-field ionization mass spectrometry. Org Geochem 15(2): 131-145. https://doi.org/10.1016/0146-6380(90)90078-E

41. Min D, Yang C, Shi R, Jameel H, Chiang V, Chang H (2013) The elucidation of the lignin structure effect on the cellulase-mediated saccharification by genetic engineering poplars (Populus nigra L. $\times$ Populus maximowiczii A.). Biomass Bioenergy 58:52-57. https:// doi.org/10.1016/j.biombioe.2013.08.019

42. Skyba O, Douglas CJ, Mansfield SD (2013) Syringyl-rich lignin renders poplars more resistant to degradation by wood decay fungi. Appl Environ Microbiol 79(8):2560-2571. https://doi.org/10.1128/ AEM.03182-12

43. Barakat A, Monlau F, Steyer J-P, Carrère H (2012) Effect of ligninderived and furan compounds found in lignocellulosic hydrolysates on biomethane production. Bioresour Technol 104:90-99. https:// doi.org/10.1016/j.biortech.2011.10.060

44. Mulat DG, Dibdiakova J, Horn SJ (2018) Microbial biogas production from hydrolysis lignin: insight into lignin structural changes.
Biotechnology for Biofuels 11:61. https://doi.org/10.1186/s13068018-1054-7

45. Dumitrache A, Akinosho H, Rodriguez M, Meng X, Yoo CG, Natzke J, Engle NL, Sykes RW, Tschaplinski TJ, Muchero W, Ragauskas AJ, Davison BH, Brown SD (2016) Consolidated bioprocessing of Populus using Clostridium (Ruminiclostridium) thermocellum: a case study on the impact of lignin composition and structure. Biotechnology for Biofuels 9(1):31. https://doi.org/ 10.1186/s13068-016-0445-x

46. Waliszewska H, Zborowska M, Stachowiak-Wencek A, Waliszewska B, Czekała W (2019) Lignin transformation of oneyear-old plants during anaerobic digestion (AD). Polymers 11(5): 835. https://doi.org/10.3390/polym11050835

47. Kim Y, Ximenes E, Mosier NS, Ladisch MR (2011) Soluble inhibitors/deactivators of cellulase enzymes from lignocellulosic biomass. Enzym Microb Technol 48(4-5):408-415. https://doi. org/10.1016/j.enzmictec.2011.01.007

48. Chen Y, Cheng JJ, Creamer KS (2008) Inhibition of anaerobic digestion process: a review. Bioresour Technol 99(10):40444064. https://doi.org/10.1016/j.biortech.2007.01.057

49. Sierra-Alvarez R, Lettinga G (1991) The effect of aromatic structure on the inhibition of acetoclastic methanogenesis in granular sludge. Appl Microbiol Biotechnol 34(4):544-550. https://doi.org/10. 1007/BF00180586

50. Fang HHP, Chen T, Chan OC (1995) Toxic effects of phenolic pollutants on anaerobic benzoate-degrading granules. Biotechnol Lett 17(1):117-120. https://doi.org/10.1007/BF00134207

51. Dou J, Xu W, Koivisto JJ, Mobley JK, Padmakshan D, Kögler M, Xu C, Willför S, Ralph J, Vuorinen T (2018) Characteristics of hot water extracts from the bark of cultivated willow (Salix sp.). ACS Sustain Chem Eng 6(4):5566-5573. https://doi.org/10.1021/ acssuschemeng.8b00498

52. Jeon SH, Chun W, Choi YJ, Kwon YS (2008) Cytotoxic constituents from the bark of Salix hulteni. Arch Pharm Res 31(8):978-982. https://doi.org/10.1007/s12272-001-1255-9

53. Palo RT (1984) Distribution of birch (Betula SPP.), willow (Salix SPP.), and poplar (Populus SPP.) secondary metabolites and their potential role as chemical defense against herbivores. J Chem Ecol 10(3):499-520. https://doi.org/10.1007/BF00988096

54. Förster N, Ulrichs C, Zander M, Kätzel R, Mewis I (2010) Factors influencing the variability of antioxidative phenolic glycosides in Salix species. J Agric Food Chem 58(14):8205-8210. https://doi. org/10.1021/jf100887v

55. Orians CM, Lower S, Fritz RS, Roche BM (2003) The effects of plant genetic variation and soil nutrients on secondary chemistry and growth in a shrubby willow, Salix sericea: patterns and constraints on the evolution of resistance traits. Biochem Syst Ecol 31(3):233-247. https://doi.org/10.1016/S0305-1978(02)00144-8

Publisher's Note Springer Nature remains neutral with regard to jurisdictional claims in published maps and institutional affiliations. 